\title{
Propostas de tempo integral: a que se destina a ampliação do tempo escolar?
}

\author{
Marília Gouvea de Miranda* \\ Soraya Vieira Santos ${ }^{* *}$
}

\section{Resumo}

$\mathrm{O}$ artigo tem por finalidade apreender e discutir os fundamentos das propostas de ampliação de tempo escolar em curso nas redes de ensino público brasileiro. É um desdobramento de um trabalho anterior (SANTOS, 2009), em que foram levantados, entre outros dados, os argumentos mais frequentemente utilizados para justificar as propostas de escola integral em curso no País. Tendo por referência essas justificativas, o artigo discute duas tendências na argumentação em defesa da implantação das redes de escola integral no País: primeiro, a escola integral assume o discurso de prevenção de risco social, incorporando a função de assistência social às responsabilidades da instituição escolar; segundo, a ampliação do tempo escolar passa a envolver açôes de atores voluntários e a incorporar novos ambientes dentro e fora da escola. Por fim, são discutidas possíveis implicações para a política de ampliação de tempo escolar em curso no Brasil, com destaque para os riscos de descaracterizaçáo do papel social da escola e a diminuição da responsabilidade do Estado diante da Educação Básica.

Palavras-chaves: Tempo escolar. Escola pública. Reforma da educação.

* Doutora em Educação pela Pontifícia Universidade Católica de São Paulo (PUC/ SP). Professora titular da Faculdade de Educação da Universidade Federal de Goiás (UFG). Coordenadora do Programa de Pós-Graduação em Educaçáo da UFG.

** Doutoranda do Programa de Pós-Graduação em Educação da Universidade Federal de Goiás (UFG). Mestre em Educaçáo pelo Programa de Pós-Graduação em Educação da UFG. Professora assistente da Faculdade de Educação da UFG. 
$\mathrm{O}$ artigo discute algumas justificativas que sustentam as propostas de ampliação de tempo escolar em curso nas redes de ensino público brasileiro e suas implicaçôes. Como se sabe, a ampliação do tempo escolar, entendida como ampliação da jornada escolar, tem sido proposta como a grande soluçâo para a escola pública brasileira, com vistas a minorar as suas dificuldades tão abundantemente conhecidas. Educadores, acadêmicos, gestores, políticos, representantes de agências multilaterais e de setores empresariais, todos parecem defender mais tempo para a criança na escola. Assim formulada, essa proposta é mesmo irretocável: quem não defenderia que a escola redobrasse sua capacidade de atendimento, permitindo que seus alunos ali permanecessem para mais uma jornada diária, desfrutando de mais tempo para sua melhor formação?

Contudo, boas ideias convertidas em políticas educacionais de alcance nacional têm condicionantes, abordagens, implicaçóes, limites e consequências que devem ser compreendidas e discutidas. Quando isso náo acontece, corre-se o risco de perder de vista o distanciamento que a análise crítica das reformas educacionais requer. Assim, na contramão das adesóes acríticas a essas reformas, propóe-se neste artigo questionar a concepçáo de escola integral e sua destinaçáo.

Essa preocupação norteou um estudo anterior realizado por Santos (2009) para uma dissertação de mestrado orientada por Marília Gouvea de Miranda - $A$ ampliação do tempo escolar em propostas de educação pública integral-, do qual esse artigo é um desdobramento. Santos analisou como a ampliação do tempo escolar foi concebida em distintas propostas de escola integral implantadas no Brasil a partir da promulgação da Lei de Diretrizes e Bases da Educação Nacional de 1996 (BRASIL, 1996), em particular as propostas em curso no ano de 2008 nas redes públicas de ensino estaduais e municipais, implantadas por iniciativa dos governos locais ${ }^{1}$. Os resultados obtidos sugerem alguns aspectos fundamentais na compreensão do tempo escolar nas políticas de ampliação da jornada escolar. O presente artigo parte desses aspectos, mas amplia e aprofunda as análises ali esboçadas, para caracterizá-las como tendências na argumentação em defesa da implantação das redes de escola integral no País.

\section{Para entender o assunto}

As propostas de ampliação do tempo escolar vinculam-se a um contexto amplo de reformas educacionais no Brasil e na América Latina, ocorridas a partir da década de 1990, quando se atribuiu à educaçấo uma posiçấo estratégica 
perante as novas demandas da reformulação produtiva em curso. Com base nessa perspectiva e em consonância com orientaçôes dos organismos internacionais que atuam na definição das políticas para a educação, a escola deve exercer funçáo específica e determinante na sustentação da competitividade necessária às condiçốes de reprodução da sociedade mercantil.

A Conferência Mundial de Educação para Todos (DECLARAÇÃO, 1990), realizada em Jomtien, Tailândia, em 1990, é considerada um marco no desencadeamento das reformas educacionais no período, ao propor significativas alteraçóes para a política educacional dos países considerados em desenvolvimento. Embora os governos participantes se comprometessem a reformar seus sistemas de ensino com o intuito de garantir, essencialmente, Educação Básica de qualidade para todos, foram muito diversas as leituras dos documentos de Jomtien, originando processos que podem ser caracterizados como reformas educativas mais vigorosas ou simplesmente como reformas pontuais, superficiais e parciais (TORRES, 1994).

No Brasil, o esforço para cumprir o acordo firmado em Jomtien (também ratificado por outros documentos internacionais) ${ }^{2}$ visou essencialmente à universalização da Educação Básica, à melhoria dos resultados da aprendizagem por meio da satisfação das necessidades básicas de aprendizagem, à redução dos índices de analfabetismo de adultos e à ampliação geral dos serviços de Educação Básica para a formação de outras competências necessárias. As reformas que se seguiram foram amplamente justificadas pela noção de que seria preciso buscar soluçóes para o ensino público brasileiro, cujo fracasso era expresso em taxas de evasão, repetência e distorção idade-série.

Sucederam-se medidas cuja finalidade era transformar o Ensino Fundamental no País e buscar índices de rendimento de escolarização mais competitivos de acordo com as indicaçóes dos organismos internacionais. Dentre diversas açóes estimuladas e implantadas pelo governo federal em parceria com as esferas estaduais e municipais, destacam-se a criação do Fundo de Manutençáo e Desenvolvimento do Ensino Fundamental e Valorizaçáo do Magistério (Fundef) ${ }^{3}$, o Programa Dinheiro Direto na Escola, o Programa Nacional do Livro Didático, os Parâmetros Curriculares Nacionais (PCNs), os sistemas de avaliação da Educação Básica e o Bolsa-Escola.

Como respostas às exigências postas para educação nesse contexto, alguns projetos se voltaram para a reorganização curricular e do tempo escolar, na tentativa de instituir um novo modelo de ensino que correspondesse ao desafio 
de estabelecer uma educação de qualidade, para além do desafio anterior de promover a universalização do ensino. Em decorrência, diversos Estados e municípios brasileiros promoveram reformas na organização escolar, com iniciativas como: progressão continuada, aprovação automática, organização da escola em ciclos de formação e, mais recentemente, organização da escola em tempo integral. Essa última implica a ampliação da jornada escolar e tem sido defendida com grande entusiasmo por diversos segmentos como uma reforma a ser estendida a todas as redes de ensino público brasileiras.

Em 2008, havia, segundo Santos (2009), pelo menos dez redes estaduais de ensino (Amazonas, Goiás, Minas Gerais, Pernambuco, Rio Grande do Sul, Santa Catarina, São Paulo, Sergipe e Tocantins, além do Distrito Federal) e oito redes municipais de ensino entre as capitais das unidades federativas do Brasil (Belo Horizonte/MG, Curitiba/PR, Goiânia/GO, Palmas/TO, Porto Alegre/RS, Recife/PE, São Paulo/SP e Vitória/ES) com projetos de escola em tempo integral em andamento por iniciativa dos governos locais. Em âmbito nacional, o Programa Mais Educação, instituído pela Portaria Interministerial no 17/2007 (BRASIL, 2007) e regulamentado pelo Decreto no 7.083/10, vem constituindo-se como estratégia do Ministério da Educação para indução da ampliação do tempo escolar nas redes estaduais e municipais de ensino, por meio da oferta de atividades optativas em diferentes áreas, ${ }^{4}$ com o objetivo de ampliar a jornada escolar nas escolas públicas para, no mínimo, sete horas diárias.

Ainda que as propostas de escola integral tenham se intensificado após os anos 2000, a defesa da escola pública em tempo integral vem de antes e tem como precursor, no Brasil, Anísio Teixeira. Foi ele quem propôs a criação da primeira escola pública brasileira com funcionamento em tempo integral, o Centro Educacional Carneiro Ribeiro ou Escola Parque, localizada no bairro da Liberdade, em Salvador (Bahia). Inaugurado em 1950, o Carneiro Ribeiro tornou-se inspiração para a construção do sistema escolar de Brasília no final da década de 1950 e início da década de 1960, e serviu de exemplo também para a experiência de escola em tempo integral realizada no estado do Rio de Janeiro na década de 1980, os Centros Integrados de Educação Pública (CIEPs).

Outras iniciativas ocorreram a partir da década de 1980 e também visavam a melhorar a qualidade do ensino por meio do aumento do tempo de presença da criança na escola, como o Programa de Formação Integral da Criança (Profic), implantado pelo governo estadual de São Paulo, e os Centros Integrados de Apoio à Criança (Ciacs), que posteriormente passaram a ser chamados de 
Centros de Atenção Integral à Criança (Caics). Mas a expansão das propostas de ampliação da jornada escolar no Brasil ocorreria particularmente após a promulgação da Lei de Diretrizes e Bases da Educação Nacional (LDB) em 1996. A lei prevê que o Ensino Fundamental no Brasil passaria a ser progressivamente ministrado em tempo integral, sendo gradativamente implantado pelos diversos sistemas estaduais e municipais do País (BRASIL, 1996).

Amplamente defendida por vários setores da sociedade para a melhoria da educação no Brasil, há cada vez mais adesōes dos governos municipais e estaduais à escola de tempo integral, com efetivo apoio do governo federal, principalmente por meio do programa Mais Educação. Entretanto, é importante interrogar acerca, por exemplo, das concepções que orientam essas reformas, dos seus fundamentos, das suas estratégias e das decorrências das experiências em curso.

Em análise das propostas de implantação de tempo integral nas escolas das redes públicas brasileiras, Cavaliere (2007) identifica quatro concepçóes que podem aparecer de modo distinto ou combinado nas referidas propostas. A primeira é a "visão de cunho assistencialista", em que a escola integral é vista como "[...] uma escola para os desprivilegiados, que deve suprir deficiências gerais da formação dos alunos" (CAVALIERE, 2007, p. 1028). A segunda é a "visão autoritária", em que a escola de tempo integral é uma instituição de retenção das crianças para prevenção ao crime. A terceira é a "concepção democrática", na qual a escola assume um papel emancipatório. E a última, a visão "multissetorial", em que a educação em tempo integral pode e deve se fazer também fora da escola.

O estudo de Santos (2009), por sua vez, identificou quatro características fundamentais para compreensão do tempo escolar nas propostas de escola integral. Primeiro, certa desresponsabilização do Estado pela educação pública, ainda que a ampliação do tempo de permanência do aluno na escola produza a aparente percepção de que o Estado está aumentando sua atuação. Segundo, uma ênfase na questáo do risco social de crianças e adolescentes, de modo que a função de proteção social se agrega às responsabilidades da instituição escolar. Terceiro, uma distinção entre escola integral e educação integral, com base na ideia de que não basta oferecer uma escola de jornada completa, é preciso ofertar uma educação integral, que extrapola o ambiente escolar. E quarto, a busca por um "novo" modelo de escola para atender às novas exigências sociais.

Tendo por referência essas justificativas, o presente artigo discute duas tendências na argumentação em defesa da implantação das redes de escola 
integral no País: primeiro, a escola integral assume o discurso de prevenção de risco social, incorporando a função de assistência social às responsabilidades da instituição escolar; segundo, a ampliação do tempo escolar passa a envolver açôes de atores voluntários e a incorporar novos ambientes dentro e fora da escola. Por fim, são discutidas as possíveis implicaçóes dessas justificativas para a política de ampliação de tempo escolar em curso no Brasil, com destaque para os riscos de descaracterização do papel social da escola e a diminuição da responsabilidade do Estado com a Educação Básica.

\section{A escola integral como prevenção de risco social}

A defesa de ampliação do tempo escolar como medida necessária para a proteção de crianças e adolescentes diante do risco social está presente em todas as propostas de escola integral analisadas por Santos (2009), com maior ou menor expressão $0^{5}$. Entende-se por situação de risco social a condição de crianças e adolescentes expostas à violência, ao uso e tráfico de drogas e a outros problemas que possam afetar sua integridade e prejudiquem seu pleno desenvolvimento. A ampliação da jornada escolar seria, portanto, uma medida preventiva com a finalidade de afastar o aluno dessas ameaças, além de propiciar $\mathrm{o}$ atendimento aos educandos em situaçáo de carência alimentar e nutricional.

A questáo do risco social está presente desde a década de 1980 nas discussóes sobre experiências de escola integral no Brasil, como retrata a pesquisa de Paro (1988) realizada em um CIEP no Rio de Janeiro e em uma escola no município de Assis/SP, em que foi implantado o Programa de Formação Integral da Criança (Profic). Os pesquisadores observaram que as principais objeçôes à implantação da escola integral se corporificam na crítica ao caráter excessivamente assistencialista dos projetos e na crítica das condiçóes concretas do ensino em nossa sociedade. Contudo, os principais argumentos em favor da proposta eram a necessidade de resolver o problema do "menor abandonado" e a insuficiência do turno de quatro horas para todo o conteúdo educativo. Os pesquisadores destacam, ainda, a importância dos projetos quanto à preocupação com as classes populares e concluem que as propostas de extensão do período diário de escolaridade no Brasil estão vinculadas às necessidades da população a serem supridas pela educação. Nesse sentido, as questôes sociais tendem a sobrepor-se à dimensão pedagógica, e, com isso, o que passa a unificar as propostas de extensão da escolaridade é a ideia "[...] da 
escola como solucionadora de problemas sociais, apoiada em alguns supostos teóricos da carência cultural" (PARO, 1988, p. 213).

Coelho e Cavaliere (2002) afirmam que a política de escola integral se fundamenta na necessidade de as classes populares manterem seus filhos na escola em uma jornada equivalente à do trabalho e na possibilidade de oferecer aos alunos não somente os insumos básicos de ler e escrever, mas também o acesso à cultura e aos programas de saúde, garantindo a ampliação total do atendimento às "crianças pobres". Também Maurício (2003, 2004), após analisar as representaçóes dos professores, alunos e pais de alunos dos CIEPs do Rio de Janeiro, conclui que os pais matriculam seus filhos no horário integral não apenas por necessidade, mas, sobretudo, por estarem convencidos de que a escola de jornada ampliada oferece melhores condiçóes de atendimento aos alunos. Entretanto, para Machado (2002, p. 227), a escola "[...] precisa evoluir de uma necessidade para uma escolha, de modo que, um dia, os pais não precisem do horário integral para seus filhos, mas que o desejem".

A destinação da escola pública ao atendimento de crianças consideradas de baixa renda, por sua vez, pode reforçar o estigma e a marginalização dos mais pobres. Stock $(2004$, p. 145), por exemplo, considera que a "[...] primeira barreira imposta aos CIEPs foi a do preconceito", exatamente por ser um tipo de escola voltado para os tidos como "pobres, pardos e sujos", de modo que na cidade de Americana/SP, onde a autora realizou sua pesquisa, os CIEPs ficaram conhecidos como "escolas de marginais". Nessa perspectiva, Pires (2007), em um estudo acerca da escola integral em Blumenau/SC, alerta para o risco de conformismo e aceitação das condiçôes precárias de as escolas implicarem "[...] a legitimação e reprodução da cultura de classes, que submete as pessoas de classes econômicas desfavorecidas a ambientes precários, como se esta fosse uma característica inerente à sua condição social” (PIRES, 2007, p. 97).

A ênfase na questão do risco social como justificativa para a ampliação do tempo escolar em propostas de tempo integral requer, assim, um questionamento ao papel reservado à escola na sociedade brasileira: caberia a essa instituição assumir a função de assistência social implícita nessa concepção de risco social? No momento em que a escola passa a ser compreendida como instituição responsável por assumir novos papéis quanto ao bem-estar físico, ao desenvolvimento social e cultural dos alunos e, ainda, de proteçấo e guarda com relação aos riscos de ordem social, é possível questionar as possibilidades que a escola tem de, efetivamente, assumir tais funçôes, em especial considerando 
que já são, em geral, tão precárias suas condições de arcar com suas atribuiçōes clássicas, constituídas a partir de fortes embates e contradiçóes ao longo de sua trajetória no mundo moderno.

Nessa perspectiva, também o princípio orientador da instituição escolar se modifica, pois a escola passa a ser cada vez mais reconhecida como um lugar para a convivência de crianças e adolescentes, orientada pelo princípio que Miranda (2005, p. 641) chamou de "princípio da socialidade" ${ }^{\text {, }}$ em contraponto ao "princípio do conhecimento" que historicamente constituiu a escola moderna. É claro que a escola não deve e não pode se fechar aos desafios que a sociedade impóe a todas as instituiçôes sociais, mas tampouco se pode desconhecer que a ampliação da jornada orientada pela finalidade de proteção do aluno diante do risco social, se isolada de outras finalidades e desprovida de condiçóes, pode contribuir para agravar ainda mais a Educação Pública neste país.

\section{A escola integral como perspectiva de novos espaços e novos atores}

Em todas as propostas de escola integral analisadas por Santos (2009), afirma-se que a ampliação da jornada é parte constitutiva, mas não a única, de uma proposta de educação integral. A escola integral seria, assim, uma escola renovada em várias dimensóes, das quais duas se ressaltam: a noção de que o espaço da escola devesse se abrir para outras esferas dentro e fora do espaço escolar e a noçáo de que novos atores devessem ganhar protagonismo por meio da ação de voluntários.

Recorrendo aos postulados de Dewey e, no Brasil, de Anísio Teixeira, para quem a educação não deveria ser uma preparação para a vida, mas a própria vida, a literatura justificadora das propostas sustenta, algumas vezes sem aprofundamento, o argumento de que a educação integral englobaria uma formação geral muito mais ampla que extrapolaria os limites da escola e envolveria todos os campos da existência humana. Desse modo, "[...] a educação integral não se resume à quantidade de horas que o aluno passa na escola, mas às experiências que a criança ali vivencia" (CASTRO; FARIA, 2002, p. 87).

É nessa perspectiva que alguns autores tendem a diferenciar "educação integral" de "escola em tempo integral", destacando que, para uma efetiva educaçáo integral (educação que englobe o conhecimento científico, a cultura, 
a saúde, os esportes, conhecimentos sobre a sociedade, entre outros), seria necessário implantar um regime de tempo integral nas escolas.

Uma escola que funcione em tempo integral não pode ser apenas uma escola de dupla jornada, com repetição de tarefas e metodologias. Se assim o for, estaremos decretando a falência dessa concepção de ensino. Ao defendermos o tempo integral, fazemo-lo a partir também de uma concepção de educação que se fundamenta na formaçâo integral do ser humano [...]; que se alicerça em atividades variadas, incluindo esportes, cultura, trabalho, artes em geral; que experiencia metodologias diversas, e ocupa todos os espaços existentes no ambiente escolar. (COELHO, 2002, p. 143).

No artigo intitulado "Educação integral: uma nova identidade para a escola brasileira?", Cavaliere (2002) afirma que as funçóes da escola vêm sendo ampliadas, de modo que seria preciso elaborar uma proposta de Educação Fundamental que corresponda às novas necessidades e problemas da escola pública. A autora assegura que, atualmente, a escola é chamada a observar um conjunto de atividades não tipicamente escolares, como as questóes de higiene, saúde, alimentação, cuidados e hábitos primários, sem dúvida, importantes para o exercício de seu papel instrucional. Contudo, a intensificação desorganizada dessas açóes com sentido educacional preliminar e pouco específico tem contribuído para uma perda de identidade da Escola Fundamental brasileira, com a associaçáo da "[...] instrução escolar a uma forte açáo no campo da socializaçáo primária e da integraçáo social de contingentes da população ainda em grande parte pouco marcados pelo ethos escolar" (CAVALIERE, 2002, p. 249).

Segundo Cavaliere (2002), as análises da Escola Nova trouxeram para o campo educacional a compreensão de que a democracia é mais que uma forma de organização das estruturas políticas, é uma forma de experiência conjunta. Recorrendo a Dewey e também a Habermas, afirma que "[...] os dois autores parecem bem próximos na importância que conferem à experiência comunicativa no desenvolvimento das formas democráticas de vida" (CAVALIERE, 2002, p. 265). Ela propóe que os seguintes elementos devam compor a vida escolar: 
a) experiências diversificadas que envolvam aspectos cognitivos, morais, estéticos, políticos e práticos; b) permeabilidade aos fenômenos da vida pública que correm fora da escola; c) permeabilidade às injunçóes sociocomunitárias locais e específicas que afetam a população infantil da escola; d) estruturas e regras definidas de maneira a envolver o conjunto da escola, ensejando um funcionamento democraticamente sustentado; d) recepção de cada indivíduo em suas múltiplas dimensóes psicológicas e sociais. (CAVALIERE, 2002, p. 266).

Nessa perspectiva, a autora conclui que, ainda que tais elementos façam parte das orientaçóes curriculares e do discurso dos professores, eles precisam ser postos em prática no cotidiano escolar, o que é possível somente com a elaboração de uma nova identidade para a Escola Fundamental pública. Para a construção dessa identidade, é preciso que a escola seja um ambiente onde crianças e adultos vivenciem experiências democráticas, por meio de um convívio intenso entre todas as partes que compóem a comunidade escolar. Ou seja, é preciso que a escola se comprometa com a educação integral, e não apenas com o tempo escolar ampliado.

Também Coelho (CAVALIERE; COELHO, 2003), em relato de pesquisa realizada com docentes de seis CIEPs no Rio de Janeiro e, especificamente, sobre a relação entre educação integral e tempo integral na escola, conclui que

[...] grande parte dos profissionais possui uma concepção de educaçáo integral pautada na integração de atividades diversificadas e de ensino. Também percebe o tempo integral como facilitador dessa integração e desse trabalho. Contudo, a enumeração de setores/áreas (cultura, esporte, lazer, artes) de atividades, sem a consequente especificação das açôes arroladas (por ex., capoeira, dança, coral - artes; vôlei, basquete - esportivas; xadrez, jogos em geral - lazer), permite-nos afirmar que os docentes nâo conhecem suficientemente as imensas possibilidades de uma concepção de educação integral e de como as atividades diversificadas na escola podem contribuir para com a formação geral do aluno, principalmente aquele que se encontra nas séries iniciais do ensino fundamental. (CAVALIERE; COELHO, 2003, p. 10). 
Reiterando a noção de que o tempo na escola não deve ser um tempo restrito à aprendizagem dos conteúdos básicos, Sampaio (2001) também recorre a uma noção ampla de educação integral. Para ela, cada aluno possui um tempo próprio para aprender, e não é possível uniformizar modos de aprendizagem, de maneira que a educação integral significa não apenas inserir novas atividades, mas compreender o tempo para além das habilidades predefinidas pela escola.

A educação escolar é compreendida, assim, em seu aspecto amplo, para além das questôes propriamente escolares ou pedagógicas. Isso significa compreender que os processos educativos náo se limitam à escola e são extensivos à família, à comunidade como um todo, e não têm início apenas com a vida escolar dos alunos. Parente (2006, p. 142) afirma:

[...] ao mudarmos o foco de discussão de escola em tempo integral para educação em tempo integral, estamos entendendo as relações intrínsecas estabelecidas pela escola com outras instituiçóes, organizaçóes e movimentos sociais, bem como a própria ampliação do conhecimento, das açóes e dos espaços escolares. Todos esses elementos, acredita-se, condicionam os tempos da escola.

A pulverização das atividades escolares por diversos ambientes, e sob a coordenação de diversas organizaçóes, em certa medida poderia significar o enfraquecimento da instituição escolar e a renúncia daquilo que é constitucionalmente público. Cavaliere (2007) revela preocupaçáo com a fragmentação que poderia advir desses diferentes ambientes incorporados à escola, ao discutir noção de educação integral "multissetorial":

O problema dos modelos que fragmentam a oferta das atividades educativas em diferentes ambientes é que a manutenção de uma referência tanto para o aluno, como para a proposta pedagógica fica, na prática, muito dificultada. A organização das atividades dependeria de inúmeros fatores e os processos de planejamento e avaliação também precisariam ser descentralizados. (CAVALIERE, 2007, p. 1030). 
Em consonância com essa fragmentação, é crescente a participação de profissionais não docentes nas escolas. Ainda que se considere que, circunstancialmente, essa prática possa ser "[...] interessante e desejável, ela aumenta as responsabilidades de planejamento, controle e avaliação, caso contrário pode-se transformar perigosamente o sistema de ensino em 'terra de ninguém"” (CAVALIERE, 2007, p. 1031).

A presença do voluntariado e das parceiras com órgãos privados ocorre com maior vigor em algumas propostas de escola integral e é menos evidente em outras. Para Santos (2009), essa tendência é recorrente nas experiências que se fundamentam na ideia de oferecer atividades extracurriculares em ambientes externos à escola, como nos municípios de Belo Horizonte/MG e Porto Alegre/RS, cujas propostas se efetivaram a partir do envolvimento de agentes comunitários e de parcerias com empresas públicas e privadas em geral.

Em seu conjunto, as propostas de escola integral em andamento no Brasil expressam a perspectiva de que a adoção do tempo integral possa contribuir para a concretização de um "novo" modelo de escola, diferente em sua forma e em seu conteúdo, e capaz de colaborar no processo de transformação da sociedade. Mas, ao mesmo tempo, a nova escola é também identificada com funções a serem supridas pela educação escolar perante as novas exigências da sociedade contemporânea, como afirma Lunkes (2004) a partir de sua pesquisa sobre a escola integral na rede particular de ensino:

A educação, porém, é hoje desafiada a olhar para a rapidez na geração de novos conhecimentos e no surgimento de problemas inéditos nas mais variadas áreas das ciências e para as mudanças na compreensão do mundo. Tudo isto está a exigir a preparação das novas geraçóes para aprender a lidar com problemas, o que implica ultrapassar a concepçáo de educaçáo que se resume em repassar conhecimentos já adquiridos, e passar a priorizar a produção do conhecimento, a preparação do aluno para lidar com problemas. (LUNKES, 2004, p. 94).

Mas o que caracteriza o "novo" nas propostas de educação em tempo integral? Nas redes públicas de ensino com propostas de escola integral em andamento no Brasil, alguns projetos envolvem desde mudanças na estrutura física e reorganização das instituiçóes escolares (como construção de novos 
prédios, incorporação de novos ambientes externos à escola e novas maneiras de utilização dos espaços existentes) até novas rotinas dos alunos em atividades relativas, essencialmente, aos esportes e às artes, em geral dissociadas das matérias escolares comuns (SANTOS, 2009).

Deve-se ressaltar que, mesmo quando as propostas anunciam a produção de um "novo" tipo de escola a partir da adoção do tempo integral, muitas experiências podem ser consideradas como adaptações das escolas regulares. Ainda que possam desenvolver aspectos diferenciados, essas propostas não rompem com a organização da escola pública brasileira e não constituem, em si mesmas, inovaçôes quanto à forma ou ao conteúdo. Entretanto, a literatura identifica experiências que se baseiam em estrutura e em proposta pedagógica novas, como o caso dos CIEPs construídos no Rio de Janeiro na década de 1980: "Os Centros Integrados de Educação Pública - CIEPs - foram criados nos ideais progressistas de educação e concebidos para realizar uma educação transformadora da sociedade. Para isso, deveriam ser uma nova escola, diferente da tradicional escola pública brasileira”. (STOCK, 2004, p. 186).

Nesse caso, as escolas possuíam proposta pedagógica específica, a arquitetura do prédio escolar construído para esse fim era diferenciada, e todo o aparato de ensino era voltado para a construção de uma nova educação. Todavia, em virtude de vários fatores cujo teor não cabe retomar aqui, o projeto que incluía uma ampla concepção de educação não foi adiante e não ressoou em satisfação para a comunidade escolar. Segundo Stock (2004), o que os pais realmente queriam era o pleno desenvolvimento do processo de escolarização de seus filhos, ou seja, que recebessem os insumos escolares básicos oferecidos em qualquer escola regular.

Paro et al. demonstram que os projetos que orientavam os CIEPs e o Profic tinham como base a ideia de que "[...] somente a escola de tempo integral pode ser considerada verdadeiramente escola; logo, deduz-se que a universalização de verdade só se daria com a escola pública de tempo integral" (PARO, 1988, p. 193). Os autores criticam o fato de a escola integral aparecer como uma instituiçấo salvadora, capaz de proteger as crianças do mundo "pervertido", e consideram que as necessidades das famílias não eram atendidas pela escola de tempo integral por dois problemas: primeiro, o problema era de ordem socioeconômica, pois muitas vezes as crianças precisavam trabalhar para ajudar no sustento da casa e, por isso, as propostas tendiam a limitar-se apenas à primeira fase do Ensino Fundamental, não alcançando os adolescentes. $\mathrm{O}$ 
segundo problema era relativo à questão educacional, uma vez que os alunos comumente não queriam frequentar o horário integral em decorrência do caráter autoritário e repressivo atribuído à escola, preferindo frequentar espaços alternativos fora do ambiente escolar.

Nessa perspectiva, os autores afirmam que, tendo como base a qualidade da escola pública oferecida no Brasil, é preciso questionar a sua extensão:

Um projeto consistente de extensão diária da escolaridade deveria começar por partir do conhecimento o mais preciso possível da realidade concreta em que se dá, hoje, o ensino público no País, no sentido de verificar a natureza da escolaridade que se pretende estender. Tal exame, ao verificar as condiçóes objetivas em que se desenvolve a educação escolar das camadas populares, levaria fatalmente à constataçáo de que náo existe, de fato, uma escolaridade passível de ser estendida. (PARO, 1988, p. 219).

Os autores afirmam ainda que qualquer mudança significativa na instituição escolar necessita da participação popular, para que sejam levados em consideração os reais interesses das amplas camadas trabalhadoras e a valorização do trabalho no interior da escola. Desse modo, apontam um caminho para superação dos problemas da qualidade da educação por meio de uma efetiva participação popular na gestão escolar, em detrimento da implantação de projetos elaborados com fins estritamente políticos.

$\mathrm{Na}$ contramáo de projetos consistentes e elaborados com a participação popular, o que frequentemente prevalece é a política do tipo "ziguezague", caracterizada pelo eleitoralismo, resultante da procura por políticas educacionais que provoquem impacto capaz de produzir resultados nas urnas; $\mathrm{o}$ experimentalismo, baseado no entusiasmo com propostas elaboradas sem bases científicas; e o voluntarismo ideológico, caracterizado pela "atitude generosa" de intencionar acabar com os problemas da educação em pouco tempo (CUNHA, 1997). Como cada governo que assume traz a ideia de um "novo" modelo e busca implantar "novas" propostas, desconsiderando, por vezes, as que estão em andamento, a descontinuidade ocasiona descrédito em relação à implantação de novos projetos. Contudo, mesmo nesse contexto, a proposta de organização da escola em tempo integral foi muitas vezes bem recebida nas unidades escolares, 
porque traz em seu bojo a referida promessa de ofertar possibilidades nunca antes alcançadas por alunos de baixa renda.

Um estudo de uma escola integral da Rede Municipal de Educação de Goiânia (SANTOS, 2009) demonstrou que o tempo escolar pode ser caracterizado pela improvisação, do ponto de vista da qualidade das açóes destinadas a preencher o tempo do aluno na escola, e pela ênfase em seus resultados imediatos e instrumentais, do ponto de vista de seus efeitos quantitativos. $\mathrm{Na}$ medida em que os processos de utilização do tempo são improvisados, e que se tem em vista o disciplinamento e o controle necessário para o "bom" funcionamento da instituição, é patente que a preocupaçáo com a qualidade do tempo escolar fica subsumida e a ênfase seja colocada sobre os processos de instrumentalização do ensino e sua quantificação.

Assim, em alguns casos, o "novo" modelo de escola ou a inovação pretendida se limita ao aumento da carga horária diária, influindo pouco nos aspectos realmente qualitativos do ensino, como currículo, relaçáo entre professor e aluno, avaliação e processo de ensino-aprendizagem. A inovação que a escola integral produz ou os "novos tempos" que apregoa, em verdade, se constituem em repetição ou ampliação do que a escola de tempo parcial já oferecia. De modo que o "novo" permanece no campo do discurso, podendo contribuir para legitimar as propostas em curso e, de certa maneira, para estabelecer um consenso em torno de sua pretensa efetividade.

\section{A descaracterização do papel social da escola e a diminuição da responsabilidade do Estado}

As consideraçóes acerca dos fundamentos e implicações das propostas de ampliaçâo de tempo escolar em curso no Brasil expóem os limites e os impasses de uma reforma que, a despeito disso, tem sido enaltecida como uma solução para problemas educacionais e sociais. Neste artigo, destacamos duas tendências na justificação da ampliação do tempo diário nas escolas de tempo integral: a escola deve reter os alunos na escola para protegê-los dos riscos sociais a que estáo sujeitos; e a escola deve ampliar a jornada diária, porque está em causa um novo modelo de escola que requer mais tempo para novas experiências que se dariam em novos ambientes dentro e, principalmente, fora da escola, com o apoio das açóes voluntárias de novos atores sociais. 
Quais seriam as implicações dessas tendências para a educação pública brasileira? Ao longo do artigo, foram sugeridas algumas consequências, mas duas delas merecem destaque: os riscos de descaracterização do papel social da escola; e a diminuição da responsabilidade do Estado diante das políticas de educaçấo pública. Uma avaliação de Parente (2006) sobre as escolas integrais na Rede Municipal de Ensino em Belo Horizonte expressa essas duas consequências:

As escolas passam a abrir suas portas para os chamados, erroneamente, processos informais, senáo em suas práticas educativas, em sua forma de perceber os sujeitos que são alvo dela. Percebem que não são o único espaço de formação de crianças, adolescentes e jovens. Mais ainda: percebem que justamente por essa variedade de espaços sociais, seus tempos são instigados à transformação, tendo em vista a revisão da própria função social que a escola vai sofrendo. A pesquisa de campo em Belo Horizonte mostrou algumas evidências de que a ampliaçáo do conceito de Educação em Tempo Integral vem sendo uma tendência em vista do entendimento de que a educação de qualidade é responsabilidade do Estado em articulação com a sociedade civil. Isso não significa retirar do Estado a sua responsabilidade e, sim, reforçar que ele assuma a condução do processo, menos para manter controle da situação, e mais para garantir o direito à educação integral em tempo integral. (PARENTE, 2006, p. 144).

Sobre o papel social da escola, deve-se ter em mente o debate ao longo de seu processo de constituição no mundo moderno. Duas referências fundamentais são as concepçóes de Durkheim (1955) e de Dewey (1979). Para o primeiro, a educação era entendida como socialização das novas geraçóes. Ele fazia clara distinção entre os fins da educação - a constituiçáo do indivíduo a partir do que a sociedade requer, os ideais sociais estudados pela emergente Sociologia e os meios, definidos pela também emergente Psicologia, que deveria elucidar os processos educacionais individuais, uma vez que eles se dáo nos indivíduos e pelos indivíduos (DURKHEIM, 1955).

Por sua vez, Dewey foi um crítico da noção de sociologização como adaptação do indivíduo à sociedade e refutava a externalidade dos fins com relação aos meios. Para ele, a função social da educação não se realiza pela 
transmissão direta dos conhecimentos, mas por meio da experiência. Assim, "[...] o fim em vista não é o alvo, e, sim, atingir-se o alvo" (DEWEY, 1979, p. 114). "Cada meio é um fim temporário até que o atinjamos. Cada fim, assim que atingido, torna-se um meio de transportar a atividade para mais além" (DEWEY, 1979, p. 114). Nesse sentido, por meio da experiência, Dewey (1979) acaba por submeter os fins aos meios, ao supor um continuum entre o indivíduo e a sociedade. Propunha uma legítima educação para todos, que unificaria a "atitude mental" dos membros da sociedade, contribuindo para abolir os privilégios. Dewey (1979) toma a sociedade democrática estadunidense como paradigma de uma sociedade que só não seria ainda plenamente democrática, porque precisaria combater as desigualdades sociais. Mas, submetidos os fins aos meios, os fundamentos dessa sociedade permanecem intocados, e a identificação entre fins e meios contribui para a naturalização dos fins inerentes a uma sociedade democrática (MIRANDA, 2007, p. 258):

Ora, uma compreensão da sociedade em suas determinaçóes históricas impóe-se para a definição dos fins das açóes humanas em um dado momento. Em uma sociedade constituída em sua base por interesses que são, em essência, antagônicos, em que os fins que se pretende auferir não podem ser manifestos e em que os fins manifestos são aparentes, os fins expressam contradiçôes e os meios para a sua efetivação são igualmente contraditórios. Requer-se, assim, que "fins" e "meios" devam ser compreendidos em suas relaçóes de contradiçấo, ainda que náo irreparavelmente cindidos. A despeito das inestimáveis contribuiçóes desses autores para a compreensão da educação no mundo contemporâneo, nem a cisão entre meios e fins operada por Durkheim, nem o continuum proposto entre esses pólos por Dewey conseguem apreender as contradiçôes aí implicadas.

Como já foi mencionado, a defesa da concepção de escola integral tem em Dewey uma importante referência. Postula-se, assim, que um novo modelo de escola não se encerraria na extensão da jornada, pois seria a experiência propiciada pela educaçáo escolar um dos seus principais fundamentos. Mas de que experiência se trata nas propostas de ampliação da jornada escolar? Que 
perspectiva teria a experiência advinda de novas ambientaçóes dentro e fora da escola? E o mais importante, qual é a avaliação que se tem da experiência que a escola brasileira vem propiciando aos seus alunos, cuja extensão é requerida?

Além disso, a intenção de proteger as crianças e adolescentes dos riscos sociais impóe um fim exterior à escola integral e o faz estabelecendo uma cisão com os meios que tornariam essa tarefa possível, numa compreensão do papel social da escola muito distante da concepçáo de Dewey.

No entanto, uma objeção que pode ser feita às propostas de ampliação do tempo diário de escolarização é a redução da atuação do Estado quanto à garantia da educação pública, uma vez que, ao passar de responsável para mero condutor do processo, como sugerido por Parente (2006), o Estado delega obrigaçóes, antes inalienáveis, do ponto de vista da consolidação e do aprimoramento da escola pública.

Essa tendência em reduzir a responsabilidade estatal está presente nas propostas de tempo integral que utilizam espaços fora da escola, e também naquelas que incentivam o trabalho voluntário nas experiências de escola integral que centralizam suas atividades dentro e fora da instituição escolar. Nesses casos, as propostas de ampliação da jornada escolar recorrem ao voluntariado com a convocação de que é preciso "fazer parte", atribuindo ao esforço individual e informal de pessoas solidárias a prerrogativa de mudar a educação e garantir escola de qualidade para todos.

Também a diminuição dos recursos para a educação em algumas experiências nas redes públicas pode ser compreendida como outra manifestação desse processo de desresponsabilização do Estado, decorrente do modo pelo qual as propostas de educação em tempo integral têm sido concebidas e implantadas. Segundo Santos (2009), na Rede Municipal de Ensino de Goiânia, por exemplo, a proposta de escola integral começou a ser implementada em 2005, em uma gestão que reduziu os investimentos na área educacional a partir de uma alteração na Lei Orgânica do Município de 1990.

O princípio da universalização da escola pública com qualidade implica a responsabilização do Estado perante as questôes educacionais. Cabe lembrar que, na ótica de Gramsci (2002), a diferenciação entre a escola frequentada pela classe dirigente e a escola destinada às classes trabalhadoras só poderia ser superada pela proposiçâo de uma escola única, absolutamente pública e de responsabilidade do Estado. Nessa perspectiva, a ampliação da jornada 
escolar e, por sua vez, o aumento do tempo das crianças na escola pública significariam, pelo menos aparentemente, que a atuação do Estado em seu papel de promover a educação formal teria sido ampliada, em particular porque a ampliaçáo da jornada favoreceria os alunos que provavelmente sáo os que dela mais necessitariam. A propósito, a literatura que discute a ampliação de tempo escolar recorre com frequência à teoria gramsciana para identificar, como expressões de um Estado ampliado, a abertura da escola para as parcerias com órgãos da iniciativa privada e o incentivo ao trabalho voluntário. Deve-se ressaltar, entretanto, que do ponto de vista da concepção de Estado na teoria de Gramsci, o conceito de sociedade civil náo pode ser compreendido como "uma acomodação a ele" (WOOD, 2003, p. 208). O risco de estabelecer esse emprego amplo do termo

[...] está no fato de a lógica totalizadora e o poder coercitivo do capitalismo se tornarem invisíveis quando se reduz todo o sistema social do capitalismo a um conjunto de instituiçôes e relações, entre muitas outras, em pé de igualdade com as associações domésticas ou voluntárias. Essa redução é, de fato, a principal característica distintiva da "sociedade civil" nessa nova encarnaçáo. O efeito é fazer desaparecer o conceito de capitalismo ao desagregar a sociedade em fragmentos, sem nenhum poder superior, nenhuma unidade totalizadora, nenhuma coerção sistêmica - ou seja, sem um sistema capitalista expansionista e dotado da capacidade de intervir em todos os aspectos da vida social. (WOOD, 2003, p. 210).

Nessa reinterpretação do conceito de sociedade civil, o capitalismo é reduzido a uma pluralidade de instituiçóes e relaçôes sociais, o que "[...] não ajuda, apenas enfraquece a força analítica e normativa da 'sociedade civil', sua capacidade de enfrentar a limitação e legitimação do poder, bem como sua utilização na orientação de projetos emancipatórios" (WOOD, 2003, p. 212).

Assim, ainda que as propostas de educação integral por meio da ampliaçâo da jornada escolar se configurem como uma reforma que poderia resultar em mais e melhor escolarização de crianças e adolescentes neste país e que possam se constituir como efetivo avanço na organizaçáo do tempo escolar, muitas concepçóes que têm orientado essas propostas desconhecem ou parecem desconhecer as contradiçóes aí implicadas. Se é indispensável a luta 
por outra escola pública, em que fosse possível ir além da mera internalização dos parâmetros reprodutivos gerais da sociedade mercantil, isso deve ser feito a partir do reconhecimento das contradições inerentes às possibilidades de a escola cumprir sua destinação social. Isso requer enfrentar os riscos que advêm da descaracterização do papel social da escola e a diminuição da responsabilidade do Estado que muitas dessas propostas encerram. Afinal, a escola integral deve significar mais escola ou "mais educação", como reconhece o programa federal de incentivo à ampliação do tempo escolar. Jamais poderá se traduzir em menos escolarização, menos institucionalização, menos responsabilidade social e menos Estado nos rumos da educação neste país.

\section{Notas}

1 Outra parte da pesquisa buscou apreender o cotidiano de uma escola integral da rede municipal de ensino de Goiânia/GO por meio de análise documental, entrevista e observação. A pesquisa empírica revelou que a característica central da organização do tempo na escola municipal em tempo integral é a improvisação, que se apresenta no cotidiano da escola por meio, por exemplo, do desconhecimento do projeto da Secretaria Municipal de Educação que fundamenta a ampliação da jornada escolar. Os resultados do estudo mostram como os professores e demais profissionais da escola precisaram improvisar açóes para "cobrir" o tempo a mais que os alunos ficariam na instituiçâo escolar, uma vez que o espaço físico não foi adaptado, não houve discussão do projeto, e sequer os profissionais e pais estavam convencidos da necessidade da jornada ampliada. A improvisaçáo também se apresenta na própria política da SME, que "resolve" implantar a proposta de ampliação do tempo, mas não promove discussóes, estudos sobre a estrutura das escolas, preparo do corpo docente, etc. (SANTOS, 2009).

2 Como exemplos, podem ser citados o documento elaborado pela Comissão Econômica para a América Latina e Caribe (CEPAL, 1990), intitulado Educación y conocimiento: eje de la transformación productiva con equidad, e o Relatório Delors (1999), encomendado pela Unesco (1999).

3 Atualmente transformado em Fundeb, Fundo de Manutenção e Desenvolvimento da Educação Básica e de Valorização dos Profissionais da Educação. 
4 A partir do projeto em curso na escola, são escolhidas atividades entre os seguintes macrocampos: acompanhamento pedagógico; educação ambiental; esporte e lazer; direitos humanos em educação; cultura e artes; cultura digital; promoção da saúde; comunicação e uso de mídias; investigação no campo das ciências da natureza e educação econômica.

5 Segundo Santos (2009), algumas experiências se justificam especificamente na necessidade desse atendimento social, como na Rede Municipal de Educação em Vitória/ES. Outras identificam essa questáo em meio a diferentes justificativas, como as propostas da Rede Estadual do Rio Grande do Sul e da Rede Municipal de Goiânia, assim como o Programa Mais Educação, proposto pelo governo federal.

6 O termo "socialidade" é empregado para ressaltar que a escola passa a ser defendida como um tempo/espaço destinado à convivência dos alunos, numa acepção distinta dos conceitos de socialização e de desenvolvimento da sociabilidade adotados pela Sociologia e pela Psicologia (MIRANDA, 2005, p. 641).

\section{REFERÊNCIAS}

BRASIL. Lei no 9394, de 20 de dezembro de 1996. Estabelece as diretrizes e bases da educação nacional. Diário Oficial [da] República Federativa do Brasil, Poder Executivo, Brasília, DF, 23 dez. 1996.

BRASIL. Portaria Interministerial no 17/2007, de 24 de abril de 2007. Diário Oficial [da] República Federativa do Brasil, Poder Executivo, Brasília, DF, 26 abr. 2007. Seção 1, p. 6.

CASTRO, Ana Rosa Viveiros de; FARIA, Lia Ciomar Macedo de. CIEP: o resgate da utopia. In: COELHO, Ligia Martha Coimbra; CAVALIERE, Ana Maria Villela (Org.). Educação brasileira e (m) tempo integral. Petrópolis, RJ: Vozes, 2002. p. 83-92.

CAVALIERE, Ana Maria Villela. Educação integral: uma nova identidade para a escola brasileira? Educação \& Sociedade, Campinas, SP, v. 23, n. 81, p. 247-270, dez. 2002. 
CAVALIERE, Ana Maria Villela. Tempo de escola e qualidade na educação pública. Educação \& Sociedade, Campinas, SP, v. 28, n.100, especial, p. 1015-1035, out. 2007.

CAVALIERE, Ana Maria Villela; COELHO, Ligia Martha. Para onde caminham os CIEPs? Uma análise após 15 anos. Cadernos de Pesquisa, São Paulo, n. 119, p. 147-174, jul. 2003.

COMISIÓN ECONÓMICA PARA AMÉRICA LATINA Y EL CARIBE (CEPAL). Educación y conocimiento: eje de la transformación productiva con equidad. Santiago de Chile, 1990. Disponível em: <http://www.eclac.org/ publicaciones/xml/0/4680/lcg1702e.html $>$. Acesso em: 2 abr. 2012.

COELHO, Ligia Martha Coimbra. Formação continuada do professor e tempo integral: uma parceria estratégica na construção da educação integral. In: COELHO, Ligia Martha Coimbra; CAVALIERE, Ana Maria Villela (Org.). Educação brasileira e(m) tempo integral. Petrópolis, RJ: Vozes, 2002. p. 133-146.

COELHO, Ligia Martha Coimbra; CAVALIERE, Ana Maria Villela (Org.). Educação brasileira e (m) tempo integral. Petrópolis/RJ: Vozes, 2002.

CUNHA, Luiz Antônio. Ensino Médio e Ensino Profissional: da fusão à exclusão. In: REUNIÃO ANUAL DA ANPED, 20., 1997, Caxambu. Anais... Caxambu, MG: ANPED, 1997. p. 1-10.

DECLARAÇÃO MUNDIAL SOBRE EDUCAÇÃO PARA TODOS. Plano de ação para satisfazer as necessidades Básicas de Aprendizagem. UNESCO: Jomtien, 1990. Disponível em: <http://unesdoc.unesco.org/ images/0008/000862/086291por.pdf>. Acesso em: 20 jan. 2012.

DELORS, Jacques. Educação: um tesouro a descobrir. São Paulo: Unesco/ MEC; Cortez, 1999. Relatório para a Unesco da Comissão Internacional sobre educação para o século XXI.

DEWEY, Jonh. Democracia e educação: introdução à Filosofia da Educaçáo. 4. ed. São Paulo: Nacional, 1979.

DURKHEIM, Émile. Educação e Sociologia. São Paulo: Melhoramentos, 1955. 
GRAMSCI, Antonio. Cadernos do Cárcere. 2. ed. Tradução de Carlos Nelson Coutinho. Rio de Janeiro: Civilizaçáo Brasileira, 2002. (Maquiavel: notas sobre o Estado e a política, v. 3).

LUNKES, Arno Francisco. Escola em tempo integral: marcas de um caminho possível. 2004. 116 f. Dissertação (Mestrado em Educação) - Universidade Católica de Brasília, Brasília, DF, 2004.

MACHADO, Flora Prata. Escola de horário integral: dia-a-dia concretizando utopias. In: COELHO, Ligia Martha Coimbra; CAVALIERE, Ana Maria Villela (Org.). Educação brasileira e(m) tempo integral. Petrópolis, RJ: Vozes, 2002. p. 211-227.

MAURÍCIO, Lúcia Velloso. Escola pública de horário integral: o que se lê, o que se vê. In: REUNIÃO ANUAL DA ANPED, 26., 2003, Caxambu. Anais... Caxambu, MG: ANPED, 2003. Disponível em: <www.anped.org. br/reunioes/26/trabalhos/luciavellosomauricio.rtf>. Acesso em: 30 abr. 2008.

MAURÍCIO, Lúcia Velloso. Literatura e representações da escola pública de horário integral. Revista Brasileira de Educação, n. 27, p. 40-56, set./dez. 2004.

MIRANDA, Marília Gouvea de. Sobre tempos e espaços da escola: do princípio do conhecimento ao princípio da socialidade. Educação \& Sociedade. Campinas, SP, v. 26, n. 91, maio/ago, 2005.

MIRANDA, Marília Gouvea de. Entre meios e fins, alguns dilemas da pesquisa em educação. Educativa, Goiânia, v. 10, n. 2, p. 253-260, jul./dez. 2007.

PARENTE, Cláudia da Mota Darós. A construção dos tempos escolares: possibilidades e alternativas plurais. 2006. 173 f. Tese (Doutorado em Educação) - Faculdade de Educação, Universidade Estadual de Campinas, Campinas, SP, 2006.

PARO, Vitor et al. Escola de tempo integral: desafio para o ensino público. São Paulo: Cortez/Autores Associados, 1988.

PIRES, Gisele Brandelero Camargo. Escola pública integrada: as impressóes dos professores e especialistas das escolas de Blumenau - SC. 2007. $154 \mathrm{f}$. Dissertação (Mestrado em Educação) - Universidade do Vale do Itajaí, Itajaí, SC, 2007. 
SAMPAIO, Carmen Sanches. Tempos entrelaçados no cotidiano da escola de Ensino Fundamental. In: REUNIÂO ANUAL DA ANPED, 24., 2001, Caxambu. Anais... Caxambu, MG: ANPED, 2001. Disponível em: <www. anped.org.br/reunioes/24/T1302538971432.DOC>. Acesso em: 30 abr. 2008.

SANTOS, Soraya Vieira. A ampliação do tempo escolar em propostas de educação pública integral. 2009. 138 f. Dissertação (Programa de PósGraduação em Educação) - Faculdade de Educação, Universidade Federal de Goiás, Goiânia, 2009.

STOCK, Suzete de Cássia Volpato. Entre a paixão e a rejeição: a trajetória dos CIEPs no Estado de São Paulo - Americana. 2004. 215 f. Dissertação (Mestrado em Educação) - Faculdade de Educação, Universidade Estadual de Campinas, Campinas, SP, 2004.

TORRES, Rosa Maria. Que (e como) é necessário aprender? Necessidades básicas de aprendizagem e conteúdos curriculares. Campinas, SP: Papirus, 1994.

WOOD, Ellen Meiksins. Sociedade civil e política de identidade. In: WOOD, Ellen Meiksins. Democracia contra capitalismo: a renovaçấo do materialismo histórico. São Paulo: Boitempo, 2003. p. 205-225. 


\section{Propositions de temps intégral: à quoi est destinée l'ampliation du temps scolaire?}

\section{Résumé}

L'article a pour but de reprendre et de discuter les fondements des propositions $d$ 'ampliation du temps scolaire en cours dans les réseaux d'enseignement public brésilien. Il a été écrit à partir d'un travail antérieur (SANTOS, 2009), dans lequel furent relevés, parmi d'autres données, les arguments le plus souvent employés pour justifier les propositions courantes dans le pays pour l'école intégrale. En se reportant à ces justifications, l'article met en cause deux tendances concernant l'argumentation en défense de l'implantation des réseaux de l'école intégrale au Brésil:Premièrement l'école intégrale assume le discours de prévention $\mathrm{du}$ risque social, joignant la fonction d'assistance sociale aux responsabilités de l'institution scolaire; puis, l'ampliation du temps scolaire en vient à engager des actions d'acteurs volontaires et à insérer de nouvelles ambiances dans et hors de l'école. Enfin, on y débat les implications possibles d'une politique d'amplification du temps scolaire en cours au Brésil, mettant en évidence les risques de faire perdre le caractère du rôle social de l'école et la diminution de la responsabilité de l'État face à l'éducation de base.

Mots-clés: Temps scolaire. École publique. Réforme de l'éducation.

\section{Proposals for Full-Time Schooling: what is the purpose of expanding school hours?}

\section{Abstract}

The article strives to understand and discuss the principles underlying the proposed extension of school hours in Brazilian public school systems. The study is a development of an earlier work (SANTOS, 2009) which analyzed the arguments most frequently used to justify the proposals for full-time schooling found in the country. With these justifications as a reference, the article discusses two trends in the arguments that defend the establishment of fulltime schooling networks in Brazil. Firstly, the discourse of the full-time school as a means to reduce social risk, as the school incorporates responsibilities for social care. Secondly, the extension of school time involves the work of volunteers and of incorporating new environments both in and outside the school. Finally, the paper discusses possible implications of the policy of extending school time in operation in Brazil, and highlights the risks of distorting the social role of the school and of reducing state responsibility for basic education.

Keywords: School time. Public school. Educational reform. 
Marília Gouvea de Miranda

E-mail:mgmiranda@uol.com.br

\section{Soraya Vieira Santos}

E-mail: soraya_vieira@hotmail.com

Recebido em: 24/5/2012

Versão final recebida em: 17/10/2012

Aprovado em: 12/11/2012 